CrossMark \&click for updates

Cite this: Chem. Commun., 2015, 51,6430

Received 12th February 2015, Accepted 5th March 2015

DOI: $10.1039 / c 5 c c 01313 e$

www.rsc.org/chemcomm

\title{
Amine-catalyzed tunable reactions of allenoates with dithioesters: formal [4+2] and [2+2] cycloadditions for the synthesis of 2,3-dihydro- 1,4-oxathiines and enantioenriched thietanes $\dagger$
}

\author{
Hai-Bin Yang, Yu-Chao Yuan, Yin Wei* and Min Shi*
}

\begin{abstract}
The chemoselective [4+2] vs. [2+2] cycloaddition between allenoates and dithioesters can be controlled by switching the nucleophilic amine catalyst. The two modes of cyclizations represent the first example of controllable and chemoselective annulations between allenoates and dienophiles catalyzed by amine. These cyclizations are useful in offering a divergent synthesis of sulfur-containing heterocycles. On the basis of this investigation, it can be realized that dithioesters with a vicinal electron-withdrawing group can react not only like a Michael acceptor but also as a ketone or imine.
\end{abstract}

Lewis base catalysis, often classified as nucleophilic catalysis, remains an active and dynamic area of interest for synthetic chemists. Allenoates as a class of attractive substrates are often used in Lewis base catalyzed reactions due to their facile preparation and diverse reactivity. ${ }^{1}$ The addition of a Lewis base to the electrophilic, sp-hybridized, $\beta$-carbon of an $\alpha$-allenic ester results in the generation of a zwitterionic enolate-like intermediate which subsequently takes part in divergent annulation reaction modes with alkene, ketone and imine, including $[3+2], 2[4+2],,^{3}[3+3]^{4}$ and $[2+2]^{5}$ annulations. However, to the best of our knowledge, thiocarbonyls have not been employed in the cycloaddition with allenoates catalyzed by phosphines or amines. In 2013, Jørgensen reported an asymmetric organocatalytic thio-Diels-Alder reaction between dienals and dithioesters via trienamine catalysis. ${ }^{6}$ Based on theoretical investigations, they suggested that this thio-DielsAlder reaction was a stepwise process rather than a concerted [4+2] cycloaddition and dithioesters with a vicinal electronwithdrawing group acted like a Michael acceptor in their reaction (Scheme 1). With these precedents in mind and in connection with our ongoing efforts on developing novel reactions using nitrogen-containing Lewis bases as nucleophilic catalysts, ${ }^{7}$ we envisaged that treating allenoates with dithioesters under the

State Key Laboratory of Organometallic Chemistry, Shanghai Institute of Organic Chemistry, Chinese Academy of Sciences, 345 Lingling Road, Shanghai 200032,

P. R. China.E-mail:weiyin@mail.sioc.ac.cn,mshi@mail.sioc.ac.cn

$\dagger$ Electronic supplementary information (ESI) available: Experimental procedures, characterization data of new compounds. CCDC 992536 and 1029698. For ESI and crystallographic data in CIF or other electronic format see DOI: 10.1039/c5cc01313e

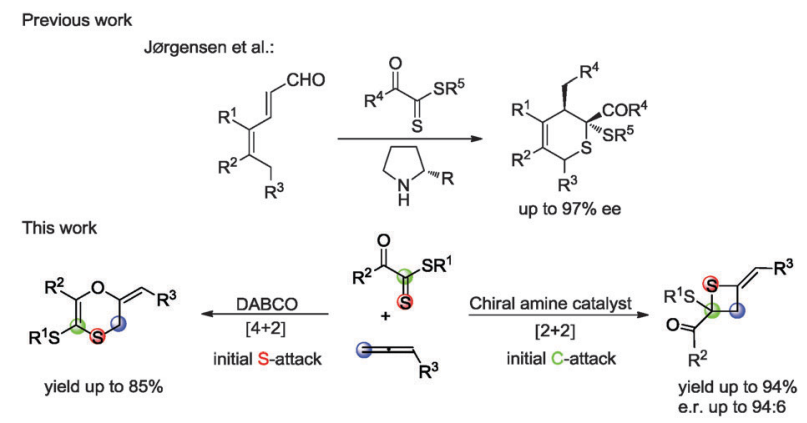

Scheme 1 Amine catalyzed cycloaddition based on thiocarbonyls.

catalysis of the nucleophilic amine might afford 2,3-dihydro-1,4oxathiine derivatives (Scheme 1).

Gratifyingly, we obtained the expected 1,4-oxathiine derivatives which were generated by a formal [4+2] cycloaddition between allenoates and dithioesters under the catalysis of DABCO. 1,4Oxathiine represents an important structural motif featured in biologically active compounds (Fig. 1). ${ }^{8}$ For example, carboxin (Vitavaxa ${ }^{\circledR}$ ) and its 4,4-dioxide analogue, oxycarboxin (Plantavaxa ${ }^{\circledR}$ ), are well known as systemic fungicides and both are the active components of many effective commercially available pesticides used worldwide to control crop smuts and rust diseases. ${ }^{9}$ Motivated by these significances, intensive investigations have been conducted to develop practically useful and step-economic methodologies to the 1,4-oxathiine architecture. ${ }^{10}$ Accordingly, the discovery of novel strategies for the synthesis of 1,4-oxathiine with good functionalgroup tolerance through simple operation is highly desirable. Besides the expected [4+2] cycloaddition products in our experiment, we could also obtain enantioenriched $[2+2]$ cycloaddition products by choosing different chiral catalysts. It remains a

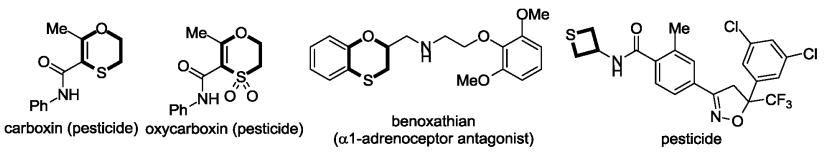

Fig. 1 Biologically active molecules containing 1,4-oxathiine or thietane. 
challenge to selectively generate different products from identical substrates, utilizing catalyst rather than substrate control. Thietanes also commonly present in a variety of natural products as well as biologically active compounds. ${ }^{11,12}$ Although thietanes can be synthesized via a lot of known methods, one-step asymmetric catalysis methodology to construct this scaffold has not been reported. ${ }^{13}$ Herein, we wish to report the amine-catalyzed tunable cycloadditions between allenoates and dithioesters.

Initial studies using dithioester $\mathbf{1 a}$ and allenoate $\mathbf{2 a}$ as the substrate were aimed at determining the reaction outcome and subsequently optimizing the reaction conditions. The results are summarized in Table 1 . We found that $[4+2]$ cycloaddition product 3a was obtained in $20 \%$ yield as a major product with concomitant formation of [2+2] cycloaddition compound $\mathbf{4 a}$ in $10 \%$ yield when the reaction was carried out in $\mathrm{CH}_{2} \mathrm{Cl}_{2}$ under the catalysis of DABCO (20 mol\%) at room temperature for $24 \mathrm{~h}$ (Table 1, entry 1). Instead of DABCO, other commonly used nitrogen-containing catalysts such as DMAP, DBU and $\mathrm{Et}_{3} \mathrm{~N}$ were also tested; however, they afforded a complex product mixture under the same reaction conditions. The examination of solvent effects using DABCO (20 mol\%) as the catalyst revealed that toluene was the solvent of choice (Table 1, entries 1-5). After extensive screening of the reaction temperature, we found that this $[4+2]$ cycloaddition was sensitive to the reaction temperature and the reaction provided compound $3 \mathrm{a}$ in $85 \%$ yield along with $4 \mathrm{a}$ in

Table 1 Optimization of reaction conditions

\begin{tabular}{|c|c|c|c|c|c|c|c|}
\hline Entry $^{a}$ & Cat. & Solvent & $T\left({ }^{\circ} \mathrm{C}\right)$ & $\begin{array}{l}\text { Yield of } \\
3 \mathbf{a}^{b}(\%)\end{array}$ & $\begin{array}{l}\text { Yield of } \\
4 a^{b}(\%)\end{array}$ & $3 \mathbf{a}: 4 \mathbf{a}^{c}$ & $\begin{array}{l}\text { e.r. of } \\
\mathbf{4} \mathbf{a}^{d}(\%)\end{array}$ \\
\hline 1 & DABCO & $\mathrm{CH}_{2} \mathrm{Cl}_{2}$ & $\mathrm{rt}$ & 20 & 10 & $2.0: 1$ & - \\
\hline 2 & DABCO & Toluene & rt & 37 & 7 & $5.3: 1$ & - \\
\hline 3 & DABCO & THF & $\mathrm{rt}$ & 36 & 4 & $9.0: 1$ & - \\
\hline 4 & DABCO & DMF & $\mathrm{rt}$ & 32 & Trace & - & - \\
\hline 5 & DABCO & $\mathrm{CH}_{3} \mathrm{CN}$ & $\mathrm{rt}$ & 33 & Trace & - & - \\
\hline 6 & DABCO & Toluene & 0 & 60 & 12 & $5.0: 1$ & - \\
\hline 7 & DABCO & Toluene & -20 & 75 & 9 & $8.3: 1$ & - \\
\hline 8 & DABCO & Toluene & -40 & 82 & 9 & $9.1: 1$ & - \\
\hline 9 & DABCO & Toluene & -40 & 85 & 9 & $9.4: 1$ & - \\
\hline 10 & Quinine & Toluene & $\mathrm{rt}$ & - & - & - & - \\
\hline 11 & $(\mathrm{DHQD})_{2} \mathrm{PHAL}$ & Toluene & $\mathrm{rt}$ & - & - & - & - \\
\hline 12 & C1 & Toluene & $\mathrm{rt}$ & - & - & - & - \\
\hline 13 & $\beta$-ICD & THF & $\mathrm{rt}$ & 30 & 30 & $1: 1.0$ & $54: 46$ \\
\hline 14 & C2 & THF & $\mathrm{rt}$ & 30 & 30 & $1: 1.0$ & $53: 47$ \\
\hline 15 & C3 & THF & $\mathrm{rt}$ & 47 & 53 & $1: 1.1$ & $68: 32$ \\
\hline 16 & C3 & Toluene & $\mathrm{rt}$ & 27 & 71 & $1: 2.6$ & $83: 17$ \\
\hline 17 & $\mathrm{C} 3$ & $\mathrm{CH}_{2} \mathrm{Cl}_{2}$ & $\mathrm{rt}$ & 28 & 68 & $1: 2.4$ & $64: 36$ \\
\hline 18 & C3 & Toluene & 0 & 33 & 65 & $1: 2.0$ & $83: 17$ \\
\hline $19^{e}$ & C3 & $\mathrm{CH}_{2} \mathrm{Cl}_{2}$ & $\mathrm{rt}$ & 27 & 70 & $1: 2.6$ & $68: 32$ \\
\hline
\end{tabular}

${ }^{a}$ Dithioester $1 \mathrm{a}(0.1 \mathrm{mmol})$, allenoate $2 \mathrm{a}(0.1 \mathrm{mmol})$, and the catalyst $(0.02 \mathrm{mmol})$ were stirred in $1 \mathrm{~mL}$ of solvent. ${ }^{b}$ Isolated yields after chromatography are shown. ${ }^{c}$ Determined by ${ }^{1} \mathrm{H}$ NMR spectroscopy. ${ }^{d}$ Determined by HPLC analysis. ${ }^{e} 10 \mathrm{~mol} \%$ of catalyst loading.
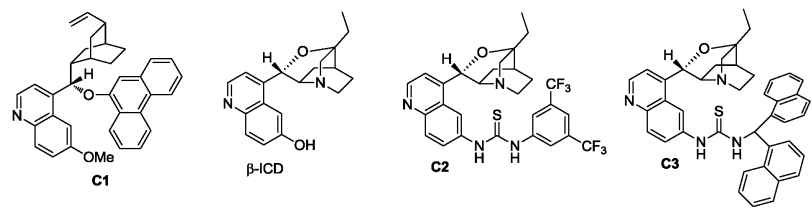

$9 \%$ yield at $-40{ }^{\circ} \mathrm{C}$. Further attempts to switch the regioselectivity to produce $4 a$ were carried out with $1 \mathrm{a}$ and $2 \mathrm{a}$ using various cinchona alkaloid-derived catalysts. Using Quinine, (DHQD) $)_{2} \mathrm{PHAL}$ or $\mathbf{C 1}$ as a catalyst, almost all starting materials 1a were recovered (Table 1, entries 10-12). When $\beta$-ICD was employed as a catalyst, this reaction could afford $4 \mathrm{a}$ in $30 \%$ yield with $54: 46$ e.r. value (Table 1, entry 13). We rationalized that the cyclic ether motif of $\beta$-ICD is critical to promote the reaction between allenoates and dithioesters because of the reduced steric hindrance around the nucleophilic nitrogen of $\beta$-ICD by restraining the conformational freedom of the bulky aromatic moiety. ${ }^{14}$ To improve the stereoselectivity, further studies were focused on the effect of the hydrogen bonding donor motif of the catalyst on this annulation reaction. Under the catalysis of $\mathbf{C 2}$ which was designed and prepared by Deng, cycloadduct $\mathbf{4 a}$ was obtained in similar results as that of $\beta$-ICD (Table 1, entry 14). ${ }^{15}$ The reaction could give better results in terms of yield and chemoselectivity in the presence of $\mathbf{C 3}$ containing a sterically hindered thiourea group (Table 1, entry 15). The examination of solvent effects using C3 (20 mol\%) as the catalyst also revealed that toluene was the solvent of choice, affording $4 a$ in $71 \%$ yield with $83: 17$ e.r. value (Table 1, entries 16 and 17). Lowering the temperature to $0{ }^{\circ} \mathrm{C}$ did not improve the enantioselectivity of this $[2+2]$ cycloaddition (Table 1 , entry 18). Reducing the catalyst loading to $10 \mathrm{~mol} \%$ had no significant influence on the reaction outcome (Table 1, entry 19).

With the optimized reaction conditions in hand, we next investigated the generality of this $[4+2]$ cyclization reaction (Table 2). As for dithioester 1, both electron-deficient (1b-1c and 1e) and electron-rich (1d and 1f) aromatic substituents at the $\alpha$-position were tolerated in this $[4+2]$ cyclization reaction although 1d and 1f afforded the desired products with lower chemoselectivity (Table 2, entries 1-5). Even for dithioester $\mathbf{1 g}$ having a naphthalen-2-yl group, the corresponding product $\mathbf{3 g}$

Table 2 Substrate scope for DABCO-catalyzed [4+2] cycloadditions between allenoates and dithioesters

\begin{tabular}{|c|c|c|c|c|}
\hline Entry $^{a}$ & $\mathrm{R}^{1}, \mathrm{R}^{2}$ & $\mathrm{R}^{3}$ & Yield of $3^{b}(\%)$ & $3: 4^{c}$ \\
\hline 1 & 1b, Me, 2-chlorophenyl & $2 \mathrm{a}, \mathrm{CO}_{2} \mathrm{Bn}$ & $3 \mathbf{b}, 73$ & $>99: 1$ \\
\hline 2 & 1c, Me, 3-bromophenyl & $2 \mathrm{a}, \mathrm{CO}_{2} \mathrm{Bn}$ & $3 c, 71$ & $17.0: 1$ \\
\hline 3 & 1d, Me, 3-methoxyphenyl & $2 \mathrm{a}, \mathrm{CO}_{2} \mathrm{Bn}$ & $3 d, 81$ & $11.0: 1$ \\
\hline 4 & 1e, Me, 4-bromophenyl & $2 \mathrm{a}, \mathrm{CO}_{2} \mathrm{Bn}$ & $3 e, 76$ & $>99: 1$ \\
\hline 5 & 1f, Me, $p$-tolyl & $2 \mathrm{a}, \mathrm{CO}_{2} \mathrm{Bn}$ & 3f, 78 & $6.0: 1$ \\
\hline 6 & 1g, Me, 2-naphthalenyl & $2 \mathrm{a}, \mathrm{CO}_{2} \mathrm{Bn}$ & $3 g, 81$ & $10.0: 1$ \\
\hline 7 & 1h, Me, 2-thienyl & $2 \mathrm{a}, \mathrm{CO}_{2} \mathrm{Bn}$ & $3 h, 52$ & $4.4: 1$ \\
\hline 8 & $\mathbf{1 i}, \mathrm{Me},{ }^{t} \mathrm{Bu}$ & $2 \mathrm{a}, \mathrm{CO}_{2} \mathrm{Bn}$ & $3 \mathbf{i}, 44$ & $1.3: 1$ \\
\hline 9 & $\mathbf{1 j}, \mathrm{Bn}, \mathrm{Ph}$ & $2 \mathrm{a}, \mathrm{CO}_{2} \mathrm{Bn}$ & $3 \mathbf{j}, 72$ & $16.0: 1$ \\
\hline 10 & $\mathbf{1 j}, \mathrm{Bn}, \mathrm{Ph}$ & $2 b, \mathrm{COPh}$ & $3 \mathbf{k}, 68$ & - \\
\hline 11 & 1b, Me, 2-chlorophenyl & $2 b, \mathrm{COPh}$ & 31,67 & - \\
\hline 12 & 1c, Me, 3-bromophenyl & 2b, COPh & $3 \mathrm{~m}, 68$ & - \\
\hline 13 & 1e, Me, 4-bromophenyl & $2 b, \mathrm{COPh}$ & $3 \mathbf{n}, 57$ & - \\
\hline 14 & 1g, Me, 2-naphthalenyl & $2 \mathbf{b}, \mathrm{COPh}$ & 3o, 45 & - \\
\hline 15 & 1h, Me, 2-thienyl & $2 b, \mathrm{COPh}$ & $3 \mathbf{p}, 43$ & - \\
\hline
\end{tabular}

${ }^{a}$ Dithioester $1(0.2 \mathrm{mmol})$, allene $2(0.2 \mathrm{mmol})$ and DABCO $(0.04 \mathrm{mmol})$ were stirred in $2 \mathrm{~mL}$ of toluene at $-40{ }^{\circ} \mathrm{C} .{ }^{b}$ Isolated yields after chromatography are shown. ${ }^{c}$ Determined by ${ }^{1} \mathrm{H}$ NMR spectroscopy. 
was furnished in $81 \%$ yield (Table 2 , entry 6 ). We were pleased to find that heteroaromatic group-substituted dithioester $\mathbf{1 h}$ was also suitable for this reaction, affording $\mathbf{3 h}$ in moderate yield (Table 2, entry 7). The structure of compound $3 \mathbf{h}$ was confirmed by X-ray diffraction. ${ }^{16}$ Furthermore, the optimized reaction conditions were also applicable to dithioester $\mathbf{1 i}$ bearing an alkyl group at the $\alpha$-position (Table 2 , entry 8 ). Using dithioester $\mathbf{1 j}$ containing a benzylthio group in this [4+2] cyclization reaction afforded $\mathbf{3} \mathbf{j}$ in $72 \%$ yield under standard conditions (Table 2, entry 9). Notably, besides allenoate 2a, 1-phenylbuta-2,3-dien-1-one 2b was also applicable to this $[4+2]$ cyclization reaction without the formation of a [2+2] cycloadduct (Table 2, entries 10-15). We reasoned that the better chemoselectivity may be caused by the stronger electron withdrawing ability of the carbonyl group in $\mathbf{2 b}$.

Using catalyst $\mathbf{C 3}$, we were able to suppress the [4+2] cycloaddition of allenoates with dithioesters and selectively access thietane products. Under the optimized reaction conditions, we next investigated the generality of this [2+2] cyclization reaction and the results are summarized in Table 3 . In the case of dithioester $\mathbf{1 g}$, the corresponding product $\mathbf{4 b}$ was obtained in $62 \%$ yield with $84: 16$ e.r. value (Table 3 ). As for $\mathbf{1 h}$, the reaction afforded thietane $4 c$ in $53 \%$ yield along with 61 : 39 e.r. value (Table 3 ). However, using dithioester $1 \mathbf{i}$ as a substrate, the reaction became sluggish so that the conversion of dithioester $1 \mathrm{i}$ was only $50 \%$ after 2 days, affording thietane $4 \mathbf{d}$ in $34 \%$ yield with $84: 16$ e.r. value (Table 3 ).

During further exploration, we found that this [2+2] cycloaddition was not only catalyst-dependent but also substrate-dependent. When 2-thioxoacetates were employed as substrates, thietanes were the exclusive products no matter what kinds of nucleophilic amine catalysts were used. In terms of controlling the enantioselectivity in this [2+2] cyclization reaction, $\beta$-ICD was better than $\mathbf{C} 3$ in this case. After simple examination, the optimal reaction conditions had been identified to carry out the reaction in toluene at $-40{ }^{\circ} \mathrm{C}$ for $24 \mathrm{~h}$ using $10 \mathrm{~mol} \%$ of $\beta$-ICD as the catalyst. As for the reaction of neopentyl 2-(methylthio)-2-thioxoacetate $\mathbf{1 l}$ with benzyl buta-2,3dienoate and ethyl buta-2,3-dienoate, the reactions proceeded smoothly to afford the corresponding products $4 \mathbf{e}$ and $\mathbf{4 f}$ in good e.r. values (Table 4). The enantioselectivity of this $[2+2]$ cyclization

Table 3 Substrate scope for C3-catalyzed asymmetric [2+2] cycloadditions between allenoates and dithioesters $s^{a, b, c, d}$

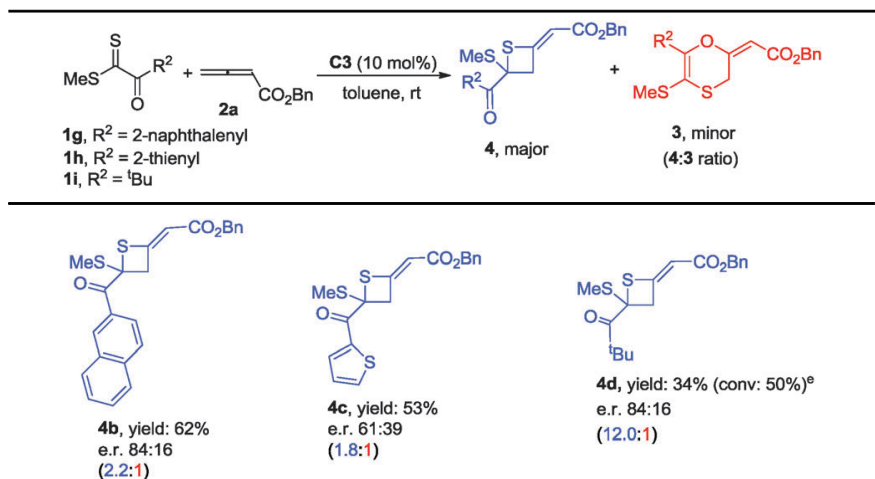

${ }^{a}$ Dithioester $1(0.2 \mathrm{mmol})$, allenoate $2 \mathrm{a}(0.2 \mathrm{mmol})$ and C3 $(0.02 \mathrm{mmol})$ were stirred in $2 \mathrm{~mL}$ of toluene at $\mathrm{rt}^{\circ}{ }^{b}$ Isolated yields after chromatography. ${ }^{c}$ Determined by ${ }^{1} \mathrm{H}$ NMR spectroscopy. ${ }^{d}$ Determined by HPLC analysis. ${ }^{e} 50 \%$ of dithioester $1 \mathbf{i}$ was recovered.
Table 4 Substrate scope for $\beta$-ICD-catalyzed asymmetric [2+2] cycloadditions between allenoates and 2-thioxoacetates ${ }^{a, b, c}$

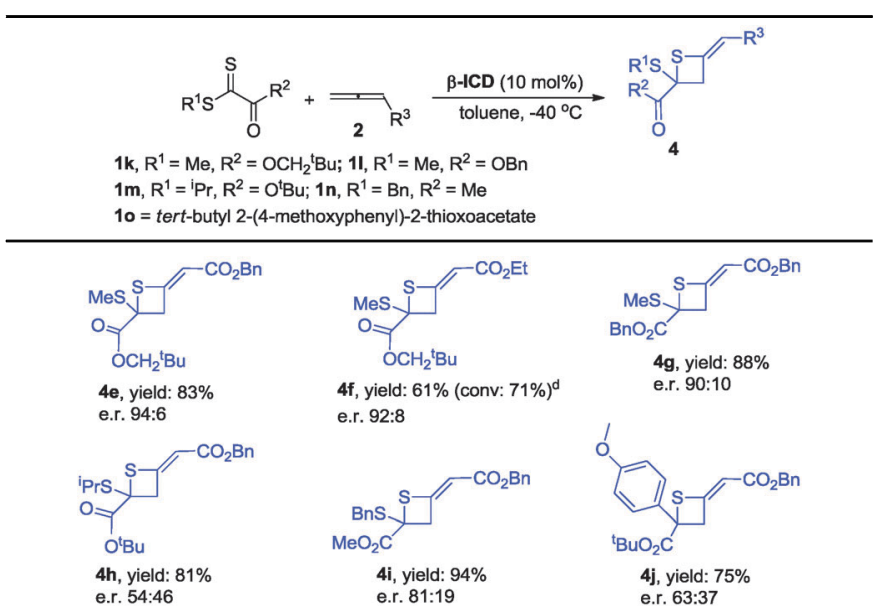

${ }^{a}$ Dithioester $1(0.2 \mathrm{mmol})$, allenoate $2 \mathrm{a}(0.2 \mathrm{mmol})$ and $\beta$-ICD $(0.02 \mathrm{mmol})$ were stirred in $2 \mathrm{~mL}$ of toluene at rt. ${ }^{b}$ Isolated yields after chromatography. ${ }^{c}$ Determined by HPLC analysis. ${ }^{d} 29 \%$ of dithioester $1 \mathbf{k}$ was recovered.

was sensitive to the substituent linked to the sulfur atom and product 4h was obtained in 54:46 e.r. value. Changing the neopentyl ester group to benzyl, and methyl ester group, the corresponding products $\mathbf{4} \mathbf{g}$ and $\mathbf{4 i}$ were obtained in good yields and good e.r. value. Notably, thioketone was also applicable to this novel $[2+2]$ cyclization reaction, affording the desired product $4 \mathbf{j}$ in good yield albeit with moderate e.r. value (Table 4).

To illustrate the synthetic utility of these obtained products, we further developed some transformations of [2+2] cycloadducts (Scheme 2). Treating $\mathbf{4 j}$ with MCPBA in $\mathrm{CH}_{2} \mathrm{Cl}_{2}$ gave sulfone $\mathbf{5 a}$ in $39 \%$ yield. Ozonation of $\mathbf{4 j}$ afforded $\beta$-thiolactone $6 \mathbf{a}$ at $-78{ }^{\circ} \mathrm{C}$ in $34 \%$ yield, which underwent ring-opening with phenylmethanamine to generate product 7a. The structure of 7a has been identified by $\mathrm{X}$-ray diffraction and the CIF data are presented in the ESI. $\dagger^{17}$

A plausible mechanism is depicted in Scheme 3 to account for the selective control. The $[4+2]$ and $[2+2]$ cyclization reactions are initiated by the formation of zwitterionic intermediate $\mathbf{A}$ via the nucleophilic addition of amine to allenoate. When amine is DABCO, the thiophilic attack of $\mathbf{A}$ on the sulfur atom of the thiocarbonyl group in $\mathbf{1}$ generates intermediate $\mathbf{B}$. The subsequent cyclization delivers product $\mathbf{3 a}$ along with the liberation of the catalyst. Based on this mechanism, the reaction of dithioesters bearing electrondeficient $\mathrm{R}^{2}$ group with allenoate is favored because the negative

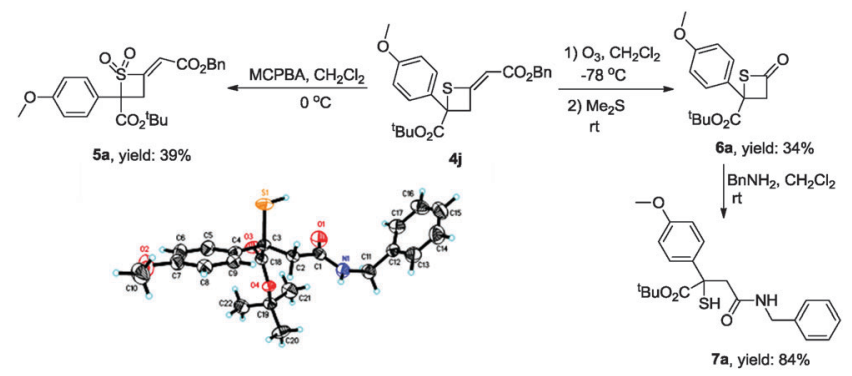

Scheme 2 The transformations of thietane $\mathbf{4 j}$ 


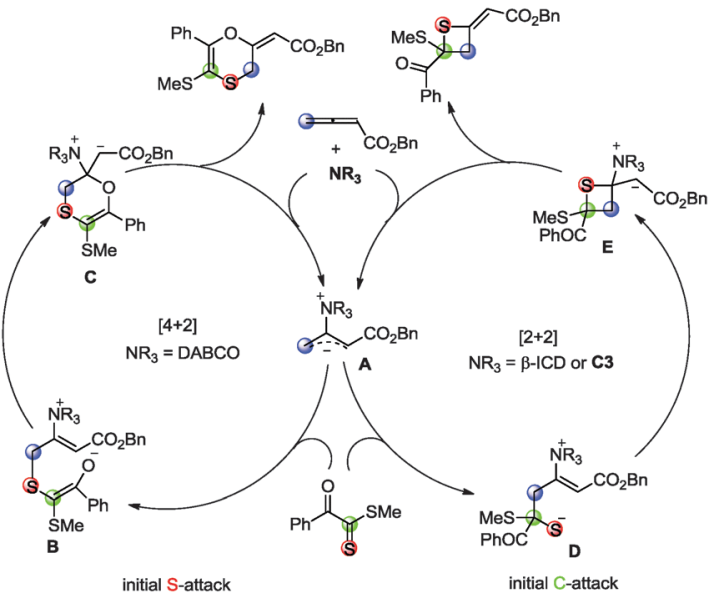

Scheme 3 Proposed mechanism
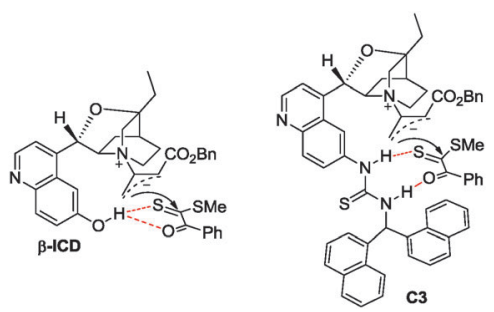

Scheme 4 Proposed hydrogen bonding interaction mode.

charge in intermediate $\mathbf{B}$ can be stabilized by delocalization. This is why they have better chemoselectivity (Table 2, entries 1 and 4). When the amine catalyst is $\mathbf{C 3}$ or $\beta$-ICD, the nucleophilic attack of zwitterionic intermediate $\mathbf{A}$ on the carbon atom of the thiocarbonyl group in $\mathbf{1}$ is preferred, perhaps due to the observation that the hydrogen bonding interaction between the catalyst with its hydrogen bonding donor and the substrate leads to the chemoselective $[2+2]$ exceeding over [4+2] cycloaddition (Scheme 4). ${ }^{18}$ Thus, the C-S bond is formed and the catalyst is released to give product $\mathbf{4 a}$.

In summary, we have developed novel amine-catalyzed tunable cycloadditions between allenoates and dithioesters, providing a divergent synthesis of 2,3-dihydro-1,4-oxathiines and enantioenriched thietanes. Through this finding, we can realize that dithioesters with a vicinal electron-withdrawing group can react not only like a Michael acceptor but also as a ketone or imine. The exploration of novel catalysts to further improve the enantioselectivity of $[2+2]$ cycloaddition between allenoates and dithioesters is underway in our laboratory.

We thank the National Basic Research Program of China (973)-2015CB856603, and the National Natural Science Foundation of China (20472096, 21372241, 21361140350, 20672127, 21421091, 21302203, 21102166, 21372250 and 20732008).

\section{Notes and references}

1 (a) M. Schmittel and C. Wohrle, J. Org. Chem., 1995, 60, 8223; (b) K. Nakatani, A. Okamoto and I. Saito, Angew. Chem., Int. Ed., 1999, 38, 3378.

2 (a) C. Zhang and X. Lu, J. Org. Chem., 1995, 60, 2906; (b) G. Zhu, Z. Chen, Q. Jiang, D. Xiao, P. Cao and X. Zhang, J. Am. Chem. Soc.,
1997, 119, 3836; (c) J. E. Wilson and G. C. Fu, Angew. Chem., Int. Ed., 2006, 45, 1426; (d) A. Voituriez, A. Panossian, N. Fleury-Brégeot, P. Retailleau and A. Marinetti, J. Am. Chem. Soc., 2008, 130, 14030; (e) H. Xiao, Z. Chai, C.-W. Zheng, Y.-Q. Yang, W. Liu, J.-K. Zhang and G. Zhao, Angew. Chem., Int. Ed., 2010, 49, 4467; $(f)$ Y. Fujiwara and G. C. Fu, J. Am. Chem. Soc., 2011, 133, 12293; $(g)$ F. Zhong, X. Han, Y. Wang and Y. Lu, Angew. Chem., Int. Ed., 2011, 50, 7837; (h) C. E. Henry, Q. Xu, Y. C. Fan, T. J. Martin, L. Belding, T. Dudding and O. Kwon, J. Am. Chem. Soc., 2014, 136, 11890.

3 (a) X. F. Zhu, J. Lan and O. Kwon, J. Am. Chem. Soc., 2003, 125, 4716; (b) R. P. Wurz and G. C. Fu, J. Am. Chem. Soc., 2005, 127, 12234; (c) Y. S. Tran and O. Kwon, J. Am. Chem. Soc., 2007, 129, 12632; (d) T. Wang and S. Ye, Org. Lett., 2010, 12, 4168; (e) X. Wang, T. Fang and X. Tong, Angew. Chem., Int. Ed., 2011, 50, 5361; $(f)$ K. D. Ashtekar, R. J. Staples and B. Borhan, Org. Lett., 2011, 13, 5732; $(g)$ X.-Y. Chen, M.-W. Wen, S. Ye and Z.-X. Wang, Org. Lett., 2011, 13, 1138; $(h)$ Z. G. Shi and T.-P. Loh, Angew. Chem., Int. Ed., 2013, 52, 8584.

4 C. Li, Q. Zhang and X. Tong, Chem. Commun., 2010, 46, 7828.

5 (a) J. B. Denis, G. Masson, P. Retailleau and J.-P. Zhu, Angew. Chem., Int. Ed., 2011, 50, 5356; (b) L. B. Saunders and S. J. Miller, ACS Catal., 2011, 1, 1347; (c) T. Wang, X.-Y. Chen and S. Ye, Tetrahedron Lett., 2011, 52, 5488; (d) S. Takizawa, F. A. Arteaga, Y. Yoshida, M. Suzuki and H. Sasai, Org. Lett., 2013, 15, 4142; (e) P. Selig, A. Turočkin and W. Raven, Chem. Commun., 2013, 49, 2930.

6 H. Jiang, D. C. Cruz, Y. Li, V. H. Lauridsen and K. A. Jørgensen, J. Am. Chem. Soc., 2013, 135, 5200.

7 (a) C.-K. Pei, Y. Jiang, Y. Wei and M. Shi, Angew. Chem., Int. Ed., 2012, 51, 11328; (b) H.-B. Yang, Y.-Z. Zhao, R. Sang and M. Shi, J. Org. Chem., 2014, 79, 3519; (c) H.-B. Yang, Y.-Z. Zhao, R. Sang, Y. Wei and M. Shi, Adv. Synth. Catal., 2014, 356, 3799.

8 (a) C. J. Paget, E. M. Dennis, J. Nelson and D. C. DeLong, J. Med. Chem., 1970, 13, 620; (b) M. Eltze, Eur. J. Pharmacol., 1996, 311, 187; (c) M. Harfenist, D. M. Joseph, S. C. Spence, D. P. C. Mcgee, M. D. Reeves and H. L. White, J. Med. Chem., 1997, 40, 2466; (d) J. B. Baell and G. A. Holloway, J. Med. Chem., 2010, 53, 2719.

9 (a) B. von Schmeling and M. Kulka, Science, 1966, 152, 659; (b) B. von Schmeling, M. Kulka, D. S. Thiara and W. A. Harrison, US Pat., 3249499, 1966 (Chem. Abstr., 1966, 65, 7190); (c) M. Kulka, Can. J. Chem., 1980, 58, 2044.

10 (a) J. Mattay and C. Dittmer, J. Org. Chem., 1986, 51, 1894; (b) W. S. Lee, H. G. Hahn and and K. D. Nam, J. Org. Chem., 1986, 51, 2789; (c) W. S. Lee, O. S. Park, J. K. Choi and K. D. Nam, J. Org. Chem., 1987, 52, 5374; (d) W. S. Lee, H. G. Hahn and K. H. Chang, J. Org. Chem., 1989, 54, 2455; (e) S. Kim and C. M. Cho, Heterocycles, 1994, 38, 1971; $(f)$ G. Capozzi, R. G. W. Franck, M. Mattioli, S. Menichetti, C. Nativi and G. Valle, J. Org. Chem., 1995, 60, 6416; $(g)$ V.-H. Nguyen, H. Nishino, S. Kajikawa and K. Kurosawa, Tetrahedron, 1998, 54, 11445; (h) S. Watanabe, E. Mori, H. Nagai, T. Iwamura, T. Iwama and T. Kataoka, J. Org. Chem., 2000, 65, 8893.

11 (a) W. C. Lo, J. E. Hunter, G. B. Watson, A. Patny, P. S. Iyer and J. Boruwa, US Pat. 171308 A1, 2014; (b) C. J. Yves, R. Peter, P. Thomas and E. Q. Myriem, WO Pat. 26931 A1, 2013; (c) S. K. Chunga, S. H. Banb, S. H. Kimb, B. E. Kimb, S. H. Woob, J. B. Summers and R. G. Conway, Bioorg. Med. Chem. Lett., 1995, 5, 1091; (d) C. H. Tilford, J. Med. Chem., 1971, 14, 1020.

12 S. Aubry, K. Sasaki, L. Eloy, G. Aubert, P. Retailleau, T. Cresteil and D. Crich, Org. Biomol. Chem., 2011, 9, 7134.

13 (a) H. Kohn, P. Charumilind and Y. Gopichand, J. Org. Chem., 1978, 43, 4961; (b) K. Nagasawa and A. Yoneta, Chem. Pharm. Bull., 1985, 33, 5048; (c) K. Muthuramu, B. Sundari and V. Ramamurthy, J. Org. Chem., 1983, 48, 4482; (d) M. Machida, K. Oda and E. Yoshida,J. Org. Chem., 1985, 50, 1681; (e) J. D. Coyle, P. A. Rapley, J. Kamphuis and H. J. Bos, J. Chem. Soc., Perkin Trans. 1, 1985, 1957.

14 Y. Iwabuchi, M. Nakatani, N. Yokoyama and S. Hatakeyama, J. Am. Chem. Soc., 1999, 121, 10219.

15 J. Song, Y. Wang and L. Deng, J. Am. Chem. Soc., 2006, 128, 6048.

16 The crystal data of $\mathbf{3 h}$ have been deposited in CCDC with number 992536.

17 The crystal data of 7a have been deposited in CCDC with number 1029698.

18 (a) K. Martinez-Mayorga, E. Juaristi and G. Cuevas, J. Org. Chem., 2004, 69, 7266; (b) J. T. Lenthall, J. A. Foster, K. M. Anderson, M. R. Probert, J. A. K. Howard and J. W. Steed, CrystEngComm, 2011, 13, 3202 . 